\title{
Supplementary material of Asymmetric impact of groundwater use on groundwater droughts
}

Doris E Wendt ${ }^{1}$, Anne F Van Loon ${ }^{1}$, John P Bloomfield ${ }^{2}$, David M Hannah ${ }^{1}$

1: University of Birmingham, Birmingham, UK

2: British Geological Survey, Wallingford, UK

\section{S1: Location and purpose of groundwater abstraction wells in the four water management units in the UK}
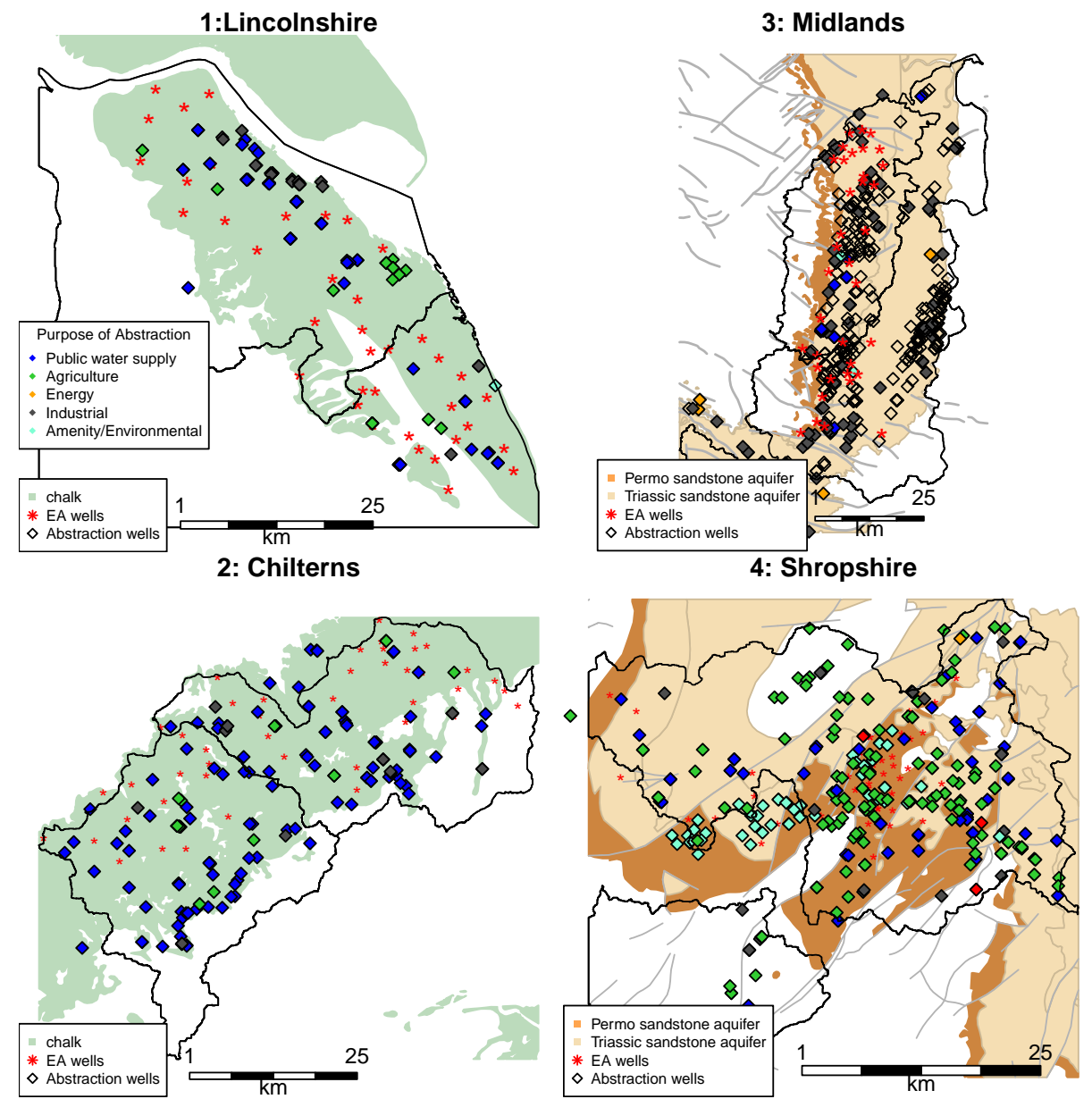

Figure S1. The location and purpose of groundwater abstraction wells in the four water management units. The coloured diamonds indicate locations of abstraction wells and the colours represent the purpose of a provided abstraction licence. Please note that some wells overlap. 

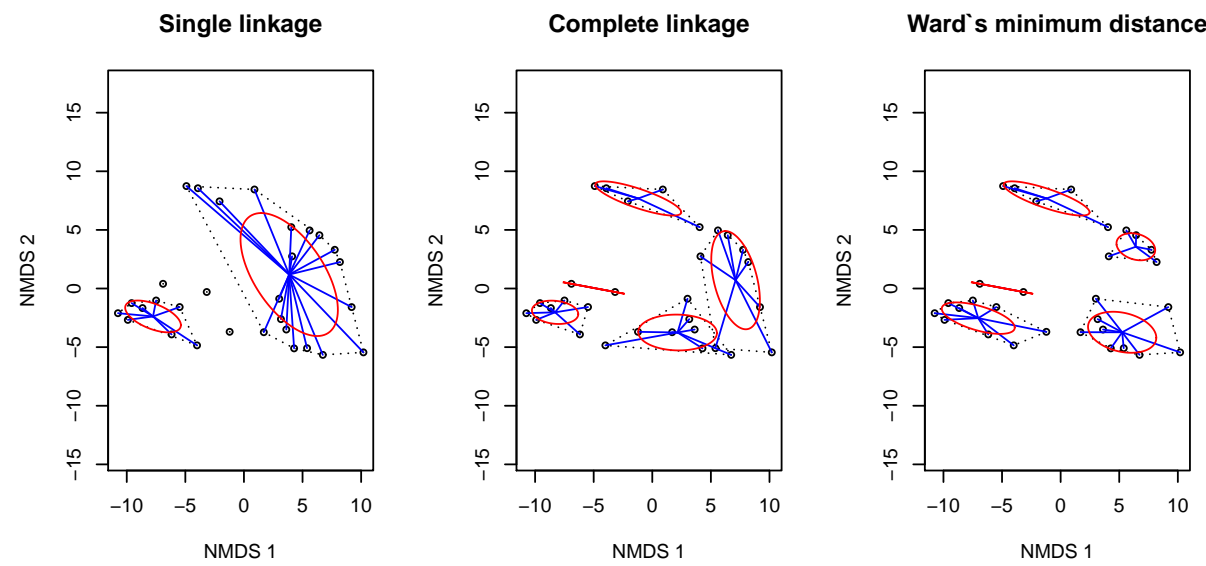

Figure S2. Cluster composition of three clustering techniques (single linkage, complete linkage, and Ward's minimum) shown for the five Chalk clusters using the matrix non-metric multidimensional scaling plot (NMDS) of the vegan package (Dixon, 2003). The clusters in Ward's minimum technique show the least overlap and are therefore selected in further analysis. 

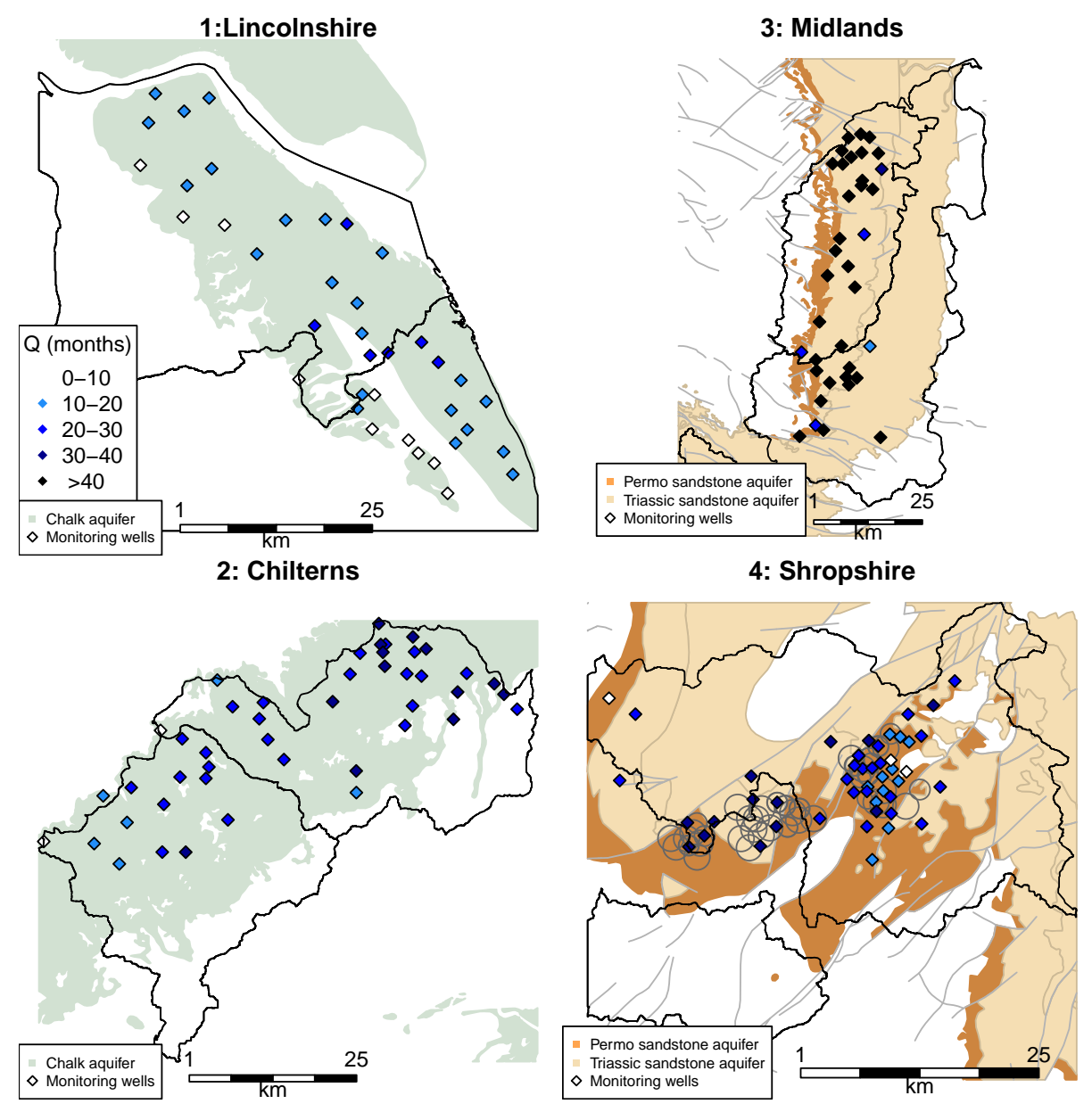

Figure S3. Accumulation period (in months) for monitoring wells in the four water management units. 


\section{References}

Dixon, P.: VEGAN, a package of R functions for community ecology, Journal of Vegetation Science, 14, 927-930, doi:10.1111/j.16541103.2003.tb02228.x, 2003. 